\title{
Long-term efficacy of autologous bone marrow mesenchymal stromal cells for treatment of knee osteoarthritis
}

\author{
José María Lamo-Espinosa ${ }^{1,2}$, Felipe Prósper ${ }^{1,2}$, Juan F. Blanco ${ }^{3}$, Fermín Sánchez-Guijo ${ }^{4}$, Mercedes Alberca ${ }^{5,6}$, \\ Verónica García ${ }^{5,6}$, Margarita González-Vallinas ${ }^{5,6}$ and Javier García-Sancho5,6*0
}

\begin{abstract}
Knee osteoarthritis is the most prevalent joint disease and a frequent cause of pain, functional loss and disability. Conventional treatments have demonstrated only modest clinical benefits whereas cell-based therapies have shown encouraging results, but important details, such as dose needed, long-term evolution or number of applications required are scarcely known. Here we have reanalyzed results from two recent pilot trials with autologous bone marrow-derived mesenchymal stromal cells using the Huskisson plot to enhance quantification of efficacy and comparability. We find that cell doses of 10,40 and 100 million autologous cells per knee provided quite similar healing results and that much of the effect attained 1 year after cell application remained after 2 and 4 years. These results are encouraging because they indicate that, apart from safety and simplicity: (i) the beneficial effect is both significant and sizeable, (ii) it can be achieved with a single injection of cells, and (iii) the effect is perdurable for years.

Trial registration: EudraCT 2009-017405-11; NCT02123368. Registered 25 April 2014_Prospectively registered, https:// clinicaltrials.gov/ct2/show/NCT02123368?term=02123368\&draw=2\&rank=1
\end{abstract}

Keywords: Osteoarthritis, Mesenchymal stem cells, Intraarticular injection, Regenerative medicine, Stem cell therapy

Osteoarthritis (OA) is the most prevalent joint disease and a frequent cause of pain, functional loss, and disability. It often becomes chronic, and conventional treatments have demonstrated only modest clinical benefits, with no lesion reversal [1]. Cell-based therapies with both autologous and allogeneic mesenchymal stromal cells (MSC) have shown encouraging results in human case reports [2-5]. We have been involved recently in two pilot clinical trials with autologous expanded bone marrow-derived MSC (BM-MSC) where the patients were treated with one single intra-articular injection of cells $[2,3,5,6]$. The trials showed feasibility, safety, strong indications of potential clinical efficacy and objective

\footnotetext{
*Correspondence: jgsancho@ibgm.uva.es

${ }^{5}$ University of Valladolid (UVa), Valladolid, Spain

Full list of author information is available at the end of the article
}

improvement of cartilage quality demonstrated by quantitative magnetic resonance imaging (MRI) T2 mapping $[2,3]$. In addition, the healing effects seemed to remain for at least $2-4$ years after cell treatment $[3,6,7]$. In the present commentary we have performed a more sophisticated analysis using the Huskisson plot [8], which permits quantification of the healing efficacy, in order to compare the different conditions tested (e.g. number of cells) and the endurance of the single shot treatments performed.

The former assay (EudraCT 2009-017405-11; NCT01183728) [2] was performed using a single dose of 40 million autologous BM-MSCs per knee. Feasibility and safety were confirmed and patients exhibited a rapid and progressive improvement of algo-functional indexes (Visual Analog Scale, VAS, and Western Ontario and McMaster Universities Osteoarthritis Index, WOMAC) original author(s) and the source, provide a link to the Creative Commons licence, and indicate if changes were made. The images or other third party material in this article are included in the article's Creative Commons licence, unless indicated otherwise in a credit line to the material. If material is not included in the article's Creative Commons licence and your intended use is not permitted by statutory regulation or exceeds the permitted use, you will need to obtain permission directly from the copyright holder. To view a copy of this licence, visit http://creativecommons.org/licenses/by/4.0/. The Creative Commons Public Domain Dedication waiver (http://creativecommons.org/publicdomain/zero/1.0/) applies to the data made available in this article, unless otherwise stated in a credit line to the data. 
that amounted $65 \%$ to $78 \%$ by 1 year, and the amelioration was maintained at the end of the second year [3]. In addition, MRI T2 relaxation measurements demonstrated a significant improvement of cartilage quality.

In the more recent similar trial (Eudra CT 2009017624-72, NCT02123368) [5, 6] one single dose containing either 10 or 100 million autologous BM-MSCs
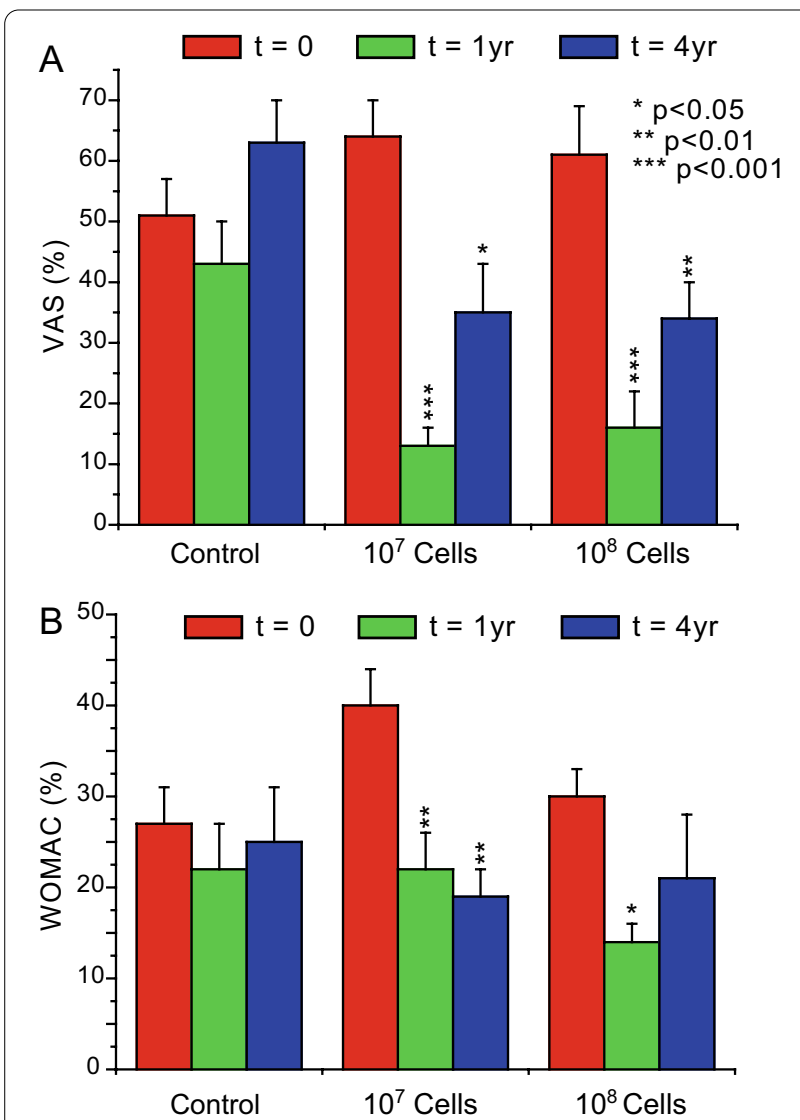

Fig. 1 Effects of BM-MSC treatment on pain (A, estimated from VAS) and disability (B, estimated from WOMAC, general index), both quantified as $\%$ of the maximum. Values (mean \pm s.e.m. of 8-9 values) before cell treatment $(t=0$; in red), 1 year after treatment $(t=1 \mathrm{yr}$, in green) and 4 years after treatment ( $t=4 \mathrm{yr}$, in blue) are compared in the controls (Gr. 1, hyaluronic acid) and in the cell-treated groups (Gr. 2 and Gr. 3, treated with either 10 or 100 million cells suspended in hyaluronic acid, respectively). Statistical significance was assayed by repeated measurements one-way ANOVA, Bonferroni multiple comparisons; NS, not significant, ${ }^{*} p<0.05 ;{ }^{* *} p<0.01,{ }^{* * *} p<0.001$ per knee was used, and compared to controls with no cells. There was no safety issues and the efficacy results were alike with both doses, and at 1 and at 4 years (Fig. 1). However, the baseline values in control and test arms were somewhat inhomogeneous (compare the three red bars in Fig. 1), and this could impair the scrutiny. (Fig. 1). However, the baseline values in control and test arms were somewhat inhomogeneous (compare the three red bars in Fig. 1), and this

A more sophisticated analysis of pain and disability can be performed through Huskisson plots [8]. In this analysis, all the patients are represented (instead of only the mean values, as in Fig. 1), and the improvements to their pain or disability are plotted against their baseline pain or disability score. The Huskisson plot leverages the weights of different baseline values, which otherwise have more or less influence depending on the baseline position within the plot. The result is a regression line where the slope represents a measure of the efficacy of the treatment. A slope of 1 (i.e., the line at $45^{\circ}$ in Fig. 2) represents complete (100\%) pain relief, the 'perfect treatment'; conversely, the horizontal line (i.e., slope of 0 ) represents no healing effect of the treatment at all.

Figure 2 shows the Huskisson plots of the different conditions from the most recent trial $[5,6]$, using the same scale for all the plots represented. To begin with, the placebo (hyaluronic acid, Fig. 2A and B) had little effect, if any, in all the conditions (Visual Analog Scale, VAS, or Western Ontario and McMaster Universities Osteoarthritis Index, WOMAC, and either after 1 or 4 years of the cell treatment). The slopes of the placebo plots ranged between -0.12 and 0.26 , and were not significantly different from zero in all the four cases (see Figure legend for details).

The cell treatments with the 10 and the 100 million cell doses improved the algo-functional indexes, but did not differ very much between them. VAS slopes were 0.79 (Fig. 2C) and 0.73 (Fig. 2E), respectively at 1 year, and 0.49 (Fig. 2C) and 0.46 (Fig. 2E) at 4 years. For WOMAC, slopes were 0.55 and 0.32 at 1 year, and 0.52 and 0.53 at 4 years (Fig. 2D and F). The slopes obtained in the Huskisson plot may also be used for comparison among different trials. It should be remarked that the slopes representing the efficacies of healing of treatments with a dose of 40 million cells was 0.65 to 0.78 after 1 year and 0.71 after 2 years $[2,3]$,

(See figure on next page.)

Fig. 2 Estimation of the efficacy of the different OA treatments from the Huskisson plot. Data were fitted to a straight line forced to pass through the origin. The slope measures the efficacy of the treatment, and values are given at the right side of the lines. Results from VAS $(\mathbf{A}, \mathbf{C}, \mathbf{E})$ and WOMAC (B, D, F) in control patients not treated with cells $(\mathbf{A}, \mathbf{B})$, and patients treated with either $10(\mathbf{C}, \mathbf{D})$ or 100 million cells $(\mathbf{E}, \mathbf{F})$ are compared. Results 1 and 4 years after cell application are given (black circles and red inverted triangles, respectively). The blue dashed lines represent no effect (horizontal, slope 0 ) and perfect treatment (45 degrees, slope, 1). Linear regression analysis and statistical significance of the slope (difference from 0 ) is given. NS, not significant, ${ }^{*} p<0.05$; ${ }^{* *} p<0.01$, ${ }^{* * *} p<0.001$; ${ }^{* * *} p<0.0001$ 
NS Not significant

${ }^{*} p<0.05$

** $p<0.01$

*** $p<0.001$

**** $p<0.0001$

A GR.1 No Cells $\stackrel{\odot-1 \text { year }}{\nabla-4 \text { years }}$

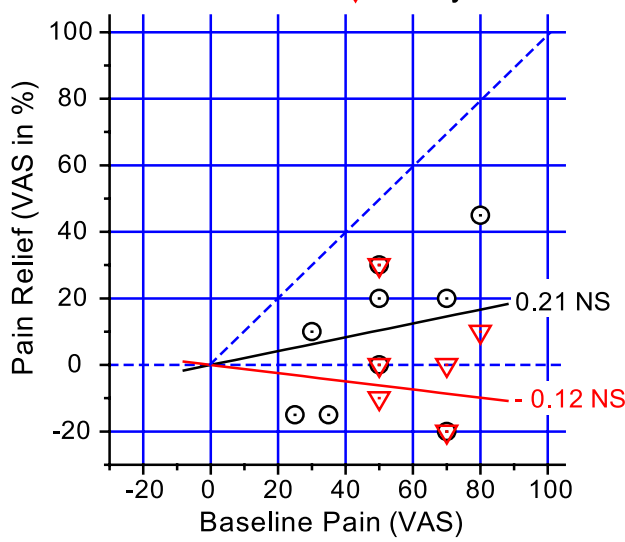

C GR. 210 million cells

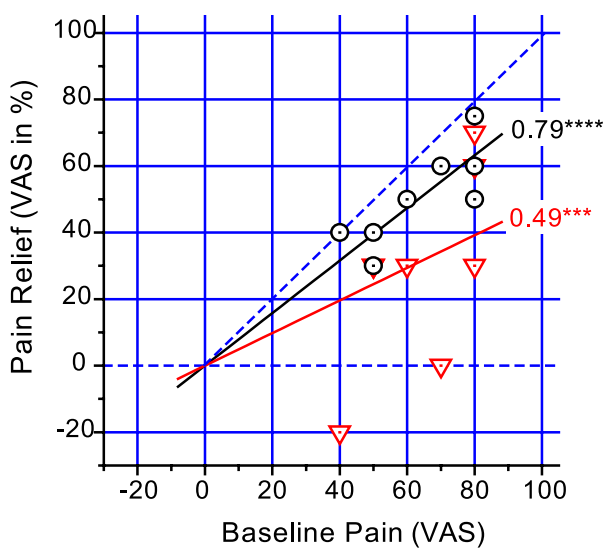

E GR.3 100 million cells

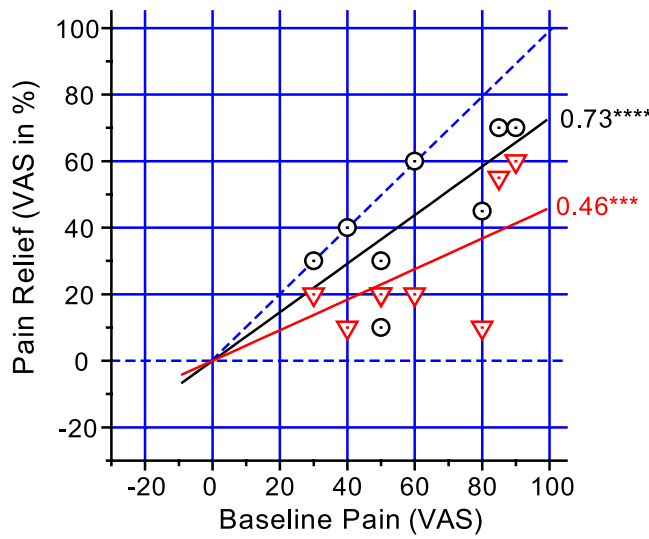

B GR. 1 No Cells $\stackrel{\odot-1 \text { year }}{\nabla-4 \text { years }}$

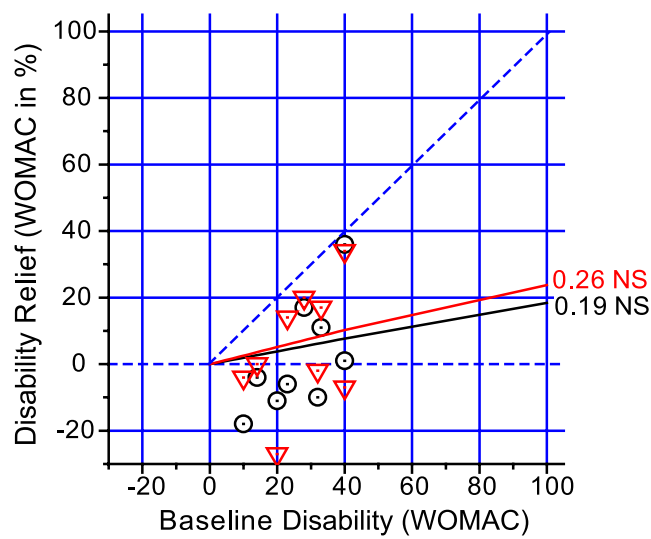

D GR. 210 million cells

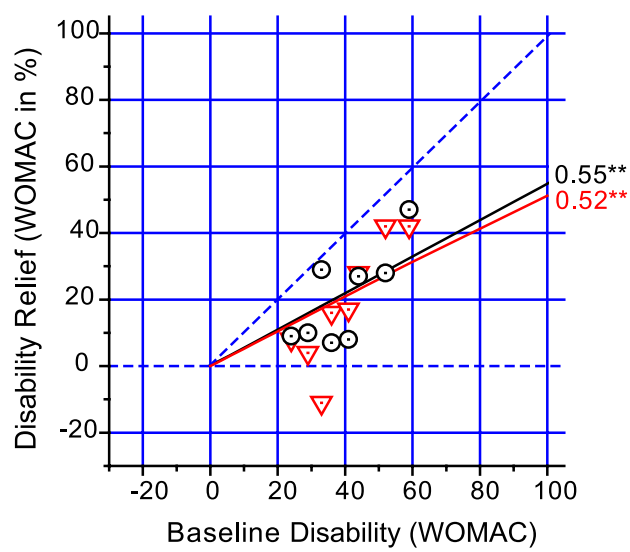

F GR. 3100 million cells

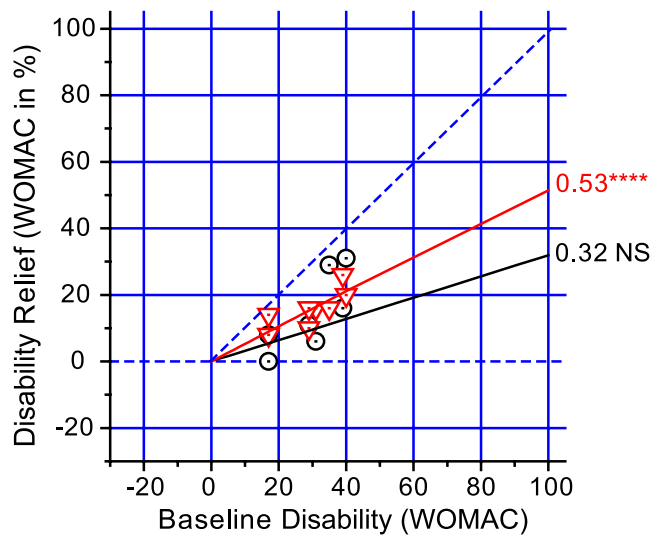

Fig. 2 (See legend on previous page.) 
so that the values obtained in the different trials were quite comparable.

In conclusion, the results of the two studies reanalysed and reviewed here demonstrate that, although the presence of the injected BM-MSCs is ephemeral [9], the beneficial effects on knee OA remain for at least 4 years [6]. The healing action seems quite similar for 10, 40 or 100 million cells doses. This unexpected result may arise from saturation of the healing effect and/or from cell damage during transport by oxygen and substrate starvation at the high cell densities used. We have preliminary results that suggest a decrease of cell viability during long storage periods at high density, even at $4{ }^{\circ} \mathrm{C}$. Long lasting effects of MSC treatments have been attributed to epigenetic actions $[9,10]$, and this mechanism could explain our results. These observations are of great practical importance as they permit to accomplish cell application with one single cell treatment, which is cheaper and more straightforward than multi-application, and does possible the administration of the cell treatment to a larger number of patients. In this regard, we have adopted this strategy in the design of a new phase III randomized clinical trial in this setting (ARTROCELL trial, with clinicaltrials.gov identifier code NCT05086939) that is currently recruiting patients.

\section{Abbreviation \\ MSCs: Mesenchymal stromal cells; BM-MSCs: Bone marrow-mesenchymal stromal cells; MRI: Magnetic resonance imaging; OA: Osteoarthritis; VAS: Visual analogue scale; WOMAC: Western Ontario and McMaster Universities Osteoarthritis Index.}

\section{Acknowledgements}

$$
\text { Not applicable. }
$$

\section{Authors' contributions}

JGS wrote the final manuscript and takes the responsibility for the integrity of the data analysis. All of the authors contributed to the conception of this paper, analysis of the results and edition of the manuscript, and read and approved its final form. All authors have read and approved the final manuscript.

\section{Funding}

This work was supported by Red de Terapia Celular of Instituto de Salud Carlos III (RETIC TerCel, RD16/0011/0003, 0005, and 0015; PIC18/00001), Centro en Red de Medicina Regenerativa de Castilla y León, and Programa Estratégico Instituto de Biología y Genética Molecular (IBGM), Escalera de Excelencia, Junta de Castilla y León (Ref. CLU-2019-02). The European Union co-financed these grants through the European Regional Development Fund. M.G.V. was supported by a Juan de la Cierva Incorporation Fellowship.

\section{Availability of data and materials}

The datasets used and/or analyzed during the current study are available from the corresponding author on reasonable request.

\section{Declarations}

\section{Ethics approval and consent to participate}

All the procedures of the original clinical trials were approved by the Institutional Review Boards of the corresponding Hospitals and by the Spanish Agency of Medicines and Medical Devices.
Consent for publication

Not applicable.

\section{Competing interests}

J.G.S. is member of the Board of Directors of Citospin, a spin-off company of the University of Valladolid (Spain) that specializes in GMP-compliant cell production. M.A. and V.G. are employees of Citospin. The other authors declare that they have no conflicts of interest.

\section{Author details}

${ }^{1}$ Orthopedic Surgery and Traumatology Department, Clínica Universidad de Navarra, Pamplona, Spain. ${ }^{2}$ Hematology and Cell Therapy Department, Clínica Universidad de Navarra, Pamplona, Spain. ${ }^{3}$ Department of Traumatology, Salamanca University Hospital, Salamanca, Spain. ${ }^{4}$ Cell Therapy Area, IBSAL-Salamanca University Hospital, University of Salamanca, Salamanca, Spain. ${ }^{5}$ University of Valladolid (UVa), Valladolid, Spain. ${ }^{6}$ Unidad de Excelencia Instituto de Biología Y Genética Molecular (IBGM), UVa-CSIC, Valladolid, Spain.

Received: 8 November 2021 Accepted: 22 November 2021

Published online: 11 December 2021

\section{References}

1. Hawker GA, Mian S, Bednis K, Stanaitis I. Osteoarthritis year 2010 in review: non-pharmacologic therapy. Osteoarthritis Cartilage. 2011;19(4):366-74.

2. Orozco L, Munar A, Soler R, Alberca M, Soler F, Huguet M, et al. Treatment of knee osteoarthritis with autologous mesenchymal stem cells: a pilot study. Transplantation. 2013;95(12):1535-41.

3. Orozco L, Munar A, Soler R, Alberca M, Soler F, Huguet M, et al. Treatment of knee osteoarthritis with autologous mesenchymal stem cells: two-year follow-up results. Transplantation. 2014;97(11):e66-8.

4. Vega A, Martin-Ferrero MA, Del Canto F, Alberca M, Garcia V, Munar A, et al. Treatment of knee osteoarthritis with allogeneic bone marrow mesenchymal stem cells: a randomized controlled trial. Transplantation. 2015;99(8):1681-90.

5. Lamo-Espinosa JM, Mora G, Blanco JF, Granero-Molto F, Nunez-Cordoba $J M$, Sanchez-Echenique C, et al. Intra-articular injection of two different doses of autologous bone marrow mesenchymal stem cells versus hyaluronic acid in the treatment of knee osteoarthritis: multicenter randomized controlled clinical trial (phase I/II). J TransI Med. 2016;14(1):246.

6. Lamo-Espinosa JM, Mora G, Blanco JF, Granero-Moltó F, Núñez-Córdoba JM, López-Elío S, et al. Intra-articular injection of two different doses of autologous bone marrow mesenchymal stem cells versus hyaluronic acid in the treatment of knee osteoarthritis: long-term follow up of a multicenter randomized controlled clinical trial (phase I/II). J Transl Med. 2018;16(1):213

7. Prodromos C, Finkle S, Rumschlag T, Lotus J. Autologous mesenchymal stem cell treatment is consistently effective for the treatment of knee osteoarthritis: the results of a systematic review of treatment and comparison to a placebo group. Medicines. 2020. https://doi.org/10.3390/ medicines7080042.

8. Huskisson EC. Measurement of pain. Lancet. 1974;2(7889):1127-31.

9. Satue M, Schuler C, Ginner N, Erben RG. Intra-articularly injected mesenchymal stem cells promote cartilage regeneration, but do not permanently engraft in distant organs. Sci Rep. 2019;9(1):10153.

10. Liu S, Liu D, Chen C, Hamamura K, Moshaverinia A, Yang R, et al. MSC transplantation improves osteopenia via epigenetic regulation of notch signaling in lupus. Cell Metab. 2015;22(4):606-18.

\section{Publisher's Note}

Springer Nature remains neutral with regard to jurisdictional claims in published maps and institutional affiliations. 